Bartın Üniversitesi

Eğitim Fakültesi Dergisi

Cilt 6, Sayı 1, s. 212-226, Şubat 2017

BARTIN - TÜRKIYE

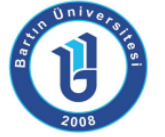

ISSN: 1308-7177
Bartin University

Journal of Faculty of Education

Volume 6, Issue 1, p. 212-226, February 2017

BARTIN - TURKEY

Doi: $10.14686 /$ buefad. 263878

\title{
2012-2016 Arasındaki Yıllarda Çevre Eğitimi Kapsamında Yayımlanan Lisansüstü Tezlerin İncelenmesi
}

Ömer Faruk ÖZBEY, Arş. Gör., i̇stanbul Aydın Üniversitesi Eğitim Fakültesi, omerozbey@aydin.edu.tr

Erdoğan ŞAMA; Yrd. Doç. Dr., Gazi Üniversitesi Eğitim Fakültesi, esama@gazi.edu.tr

Öz: Araştırma 2012-2016 arasındaki yıllarda çevre eğitimi ile ilgili yayımlanmış olan yüksek lisans tezleri ve doktora tezlerindeki genel yönelimleri belirlemek amacıyla yapılmıştır. Bu çalışma betimsel bir çalışma olup araştırma çerçevesinde YÖK Ulusal Tez Merkezi veri tabanı taranmış; 53 yüksek lisans ve 12 doktora tezi olmak üzere toplamda 65 tez incelenmiştir. Çalışmadaki veriler analiz edilirken betimsel istatistik kullanılmıştır. 2012-2016 arasındaki yıllarda çevre eğitimi kapsamında en fazla tezin Gazi Üniversitesi'nden yayımlandığı görülmüştür. Tezlerde en fazla tercih edilen çalışma grubunun ilköğretim ve ortaöğretim öğrencileri olduğu; araştırma konusu olarak en fazla tercihin çevreye yönelik tutum ve çevre sorunları olduğu; araştırma yöntemi olarak en fazla tercihin tarama modeli olduğu; veri toplama tekniği açısından en fazla tercihin yazılı veri toplama olduğu; veri analizine bakıldığında ise parametrik testlerin ve betimsel/içerik analizinin tercih edildiği sonuçlarına ulaşılmıştır. Araştırmanın son kısmında sonuçlar değerlendirilmiş ve çevre eğitimi kapsamında çalışacak olanlara yönelik öneriler sunulmuştur.

Anahtar Kelimeler: çevre eğitimi, tez inceleme, çevre, betimsel analiz, durum çalışması

\section{Investigation Graduate Environmental Education in the Context of Theses Published between the Years 2012-2016}

Abstract: Research, which was published on environmental education in the years between 2012-2016 and is designed to determine general trends in the master's thesis and doctoral thesis. This study is a descriptive study scanned the data base of the National Council of Higher Education Thesis Center in the framework of research; 53 master's and 12 doctoral thesis, including a total of 65 theses were examined. While analyzed the data in the study, descriptive statistics were used. Findings showed that the maximum release from Gazi University. Research has been shown to be the most preferred primary school students of the working group; as a research subject was attitude towards the environment; method was descriptive survey model; descriptive parametric tests / content analysis. In the last part of the study evaluated the results and recommendations are offered for those who will work within the scope of environmental education. case study

Key Words: environmental education, thesis examination, environment, descriptive analysis, 


\section{GiRiş}

Çevre sözcüğünün insanlar arasında çok farklı tanımlamaları bulunmaktadır. Bu sözcüğün asıl anlamı evrenseldir. Toplumdan topluma ya da bireyler arasında fark bulunmamasıdır. Çevre dediğimiz şey genel olarak; "Yaşayan canlıları ya da canlı gruplarını ömürleri süresince etkileyen canlı ve cansız dış etkenlerin ve faktörlerin bütünüdür." (Yıldız, Sipahioğlu ve Yılmaz, 2008).

Geçmiş zamandan günümüze doğru bakıldığında bilim ve teknolojinin hızlı ilerlemesi; bireylerin yaşam kalitesini yükseltirken doğada pek çok şeyi aşırı istismar etmektedir (Yılmaz, Morgil, Aktuğ, \& Göbekli, 2002; Şahin, Cerrah, Saka, \& Şahin, 2004). Ayrıca insanlarda doğaya hüküm sürme mantığı arttığı sürece, doğal çevre ile yaşanan sorunların da aynı oranda arttığı görülmektedir. Özellikle 20. yüzyılın son çeyreğinde çevreyi dikkate almadan gelişen sanayi, artan nüfus, köyden şehirlere göçlerle oluşan çarpık kentleşmeler doğal çevrede bazı sorunların çıkmasına neden olmuştur. "Çevre sorunları" diye anılan sorunların daha fazla önemsenmesine yol açılmıştır (Erten, 2005; Ertürk, 2009; Görmez, 2010).

Ertürk'e (2009) göre çevre sorunları insanların doğal çevre üzerinde kendi oluşturdukları yapay çevrenin bıraktığı etkileridir. Bu tanımlamayla toplumun normalde doğal çevreninmiş gibi gözüken sorunlarda pay sahibi olduğu belirtmiştir. Yıldız vd. (2008) özellikle I. ve II. Dünya Savaşlarından sonra çevreye verilen zararların toplumu çevre hakkında araştırmaya yönlendirdiğini belirtmiştir.

1960'lı yıllarda yapılan derinlemesine araştırmalar göstermiştir ki dünya çok büyük çevre sorunları yaşamaktadır. Buna bağlı olarak da gelecekle ilgili tahminde bulunan araştırmacılar bu sorunların giderek daha da şiddetleneceğini ve sonunda küresel felaketlere yol açacağını öngörmüşlerdir. Bu noktadan sonra insanlar arasında doğayı korumacı yaklaşım gelişmiştir. Çevrenin evrensel bir kavram olduğu ve bunun sorunlarının herkesi ilgilendirdiği gerekçesiyle uluslararası birtakım çalışmalar yapılmıştır. 1972 yılında yapılan "Stockholm BM Insan - Çevre Konferansı" bu konuda atılmış ilk geniş çaplı adımdır (Stockholm Declaration, 1972; Yıldız vd., 2008).

Bu adımlar sonucunda çevre sorunlarının sadece belli bir kesimi değil yaşayan her canlıyı etkileyeceği ve bundan dolayı çevreye bütün dünyanın sahip çıkması gerektiği anlayışına ulaşılmıştır (Yılmaz vd., 2002; Yıldız vd., 2008; Özdemir, 2010). Bunu düzeltebilmek içinse uluslararası bir çevre eğitimi programı gerekliliği vurgulanmıştır. Sonuç olarak United Nations Environment Programme (UNEP) 1975'te "Uluslararası Çevre Eğitim Programı" yürürlüğe koymuştur. Çevre eğitiminin gerekliliği doğrultusunda hedef kitle olarak 7'den 70'e herkes kapsama dâhil edilmiştir. Bu kitleye verilmesi amaçlananlar çevreye karşı duyarlılığın evrensel olması ve yardım etme konusunda gönüllü olmalarıdır (Yıldız vd., 2008). Bu kapsamda çevre eğitimi konusunun toplumda çevreye karşı bilincini arttırmayı ve bu çevreyi muhafaza etmek için gerekli sınırları belirlemeyi içermektedir. Bunun için de 7'den $70^{\prime}$ e bütün insanların bir bütün olarak oluşan çevre sorunlarının giderilmesine uğraşılmalı ve bu medeni bir şekilde halledilmelidir. Çevre eğitimiyle verilmek istenilen çevre hakkında bilgiden ziyade insanların çevreye karşı davranışlarını düzeltmeye yönelik olduğu söylenmektedir (Önder ve Özkan, 2013; UNESCO, 1977; Stapp, 1969).

1970'li yıllardan sonra çevre eğitimi birçok ülkede bütün öğretim kademelerinde olduğu gibi yükseköğretim düzeyinde de ele alınmaya başlanmıştır (ileri, 1998; Ünal \& Dımışkı, 1999). Bu kapsamda ele alınan çevre eğitiminde amaç, öğrencilerin çevre sorunlarına karşı alternatif gelişim yollarını öngörmelerini ve bu hedeflere göre hareket etmelerini sağlamaktır (Jensen \& Schnack, 2006). Bu doğrultuda ülkemizde diğer ülkelerde olduğu gibi çevre eğitimi 
her geçen yıl daha da önem kazanmıştır. Son yıllarda çevre eğitimine duyulan bu ilgi literatür zenginliğine yol açmıştır (Leeming, Dwyer, Porter \& Cobern, 1993).

Son on yılda Sadece çevre eğitiminde değil birçok alanda teknolojinin de ilerlemesiyle bilgiye olan erişim artmakta ve yapılan çalışmaların sayısı hızla çoğalmaktadır (Akdemir \& Karakuş, 2016; Onwuegbuzie, \& Daniel, 2003). Bu süreç içerisinde hazırlanan tezler ise birçok çalışmaya rehber olmakla birlikte literatürdeki var olan sorunlara çözüm üretmektedir (Ergun \& Cilingir, 2013). Fakat yeni çalışma yapacak araştırmacıların nicel olarak çok sayıda olan bu tezlerde genel eğilimin ne olduğunu saptamaya çalışmaları zorlaşabilmektedir. Karadağ’a (2009) göre bir alanda yayınlanmış olan tezlerin incelenmesi o alanın genel çerçevesini ve nerelere kadar değinildiğini bizlere söyleyebilir, o alanın portresini bize çıkarabilir. Ayrıca, çoğu araştırmacı, kavramsal ve teorik çerçevelerinin geliştirilmesinde önceki araştırmalardaki anahtar bulguların özetlendiği nitel (örn. içerik analizi) inceleme çalışmalarından yararlanmaktadır (Onwuegbuzie, \& Daniel, 2003). Şimşek vd. (2007) yaptıkları çalışmada alanın tarihsel gelişimini ve eğilimini bulmak için bakılması gereken yerlerin o alandaki yayınlanmış tezler olduğunu ifade etmiştir. Bu tezlerin odaklandığı konular ve bulguların alanın tarihsel gelişimi üzerinde sağlam bir etkisi olduğu belirtilmektedir. Bunlara dayanarak yapılacak olan tez incelemelerinin alandaki doygunluğa ulaşmış konuları belirlemede, günümüzdeki araştırmacıların daha çok hangi konular üzerine eğildiklerine ve son olarak yeni yapılacak araştırmalarda ihtiyacın gözler önüne serilmesinde yararlı olacağını belirtmektedir (Turna \& Bolat, 2015; Kozikoğlu \& Senemoğlu, 2015; Şimşek vd., 2008; Şimşek vd., 2009; Erol \& Tüzel, 2015; Göçen \& Okur, 2015; Duygulu \& Sezgin, 2015; Şahin, Calp, Bulut \& Kuşdemir, 2013; Geçit \& Kartal, 2010; Karkın, 2011; Büyükikiz, 2014; Sümer, 2009; Yılmaz, Aydın \& Bahar, 2015; Keçeli \& Sarıusta, 2014; Yaşar \& Papatğa, 2015; Sevinç, 2013; Toptaş, 2013).

Çevre ile ilgili olarak bu alanda yapılmış çalışmalara bakıldığında Leeming vd. (1993) 1974-1993 yılları arasında çevre eğitimi üzerine yapılmış deneysel 34 çalışmayı sınıf içi ve dışı programlar başlığı altında incelemiş ve bu çalışmaların etkililiğini tartışmıştır. Sümer (2009)'in çevre ve çevre sorunun yerel yönetimlerle birlikte ele alındığı tezleri incelediği ve yerel yönetimlerin içinde çevre sorunlarına ne düzeyde yer verdiklerini belirlemeye çalıştığı görülmüştür. Ayrıca Yılmaz vd. (2015)'nin 1992-2011 yılına kadar yayımlanmış çevre eğitimi ile ilgili tezleri incelediğini ve bunlara dayalı olarak araştırma sonunda elde edilen bulguların ışığında yeni çalışacak olan araştırmacılara tavsiyeler niteliğinde olduğu görülmüştür. Fakat literatür tarandığında 2012'den günümüze kadar olan zaman diliminde çevre eğitimi konusunda yayımlanmış lisansüstü tezleri değerlendiren herhangi bir çalışmaya rastlanmamıştır. Yapılacak olan çalışma Yılmaz vd.'nin (2015) yaptığı çalışmanın bir devamı ve tamamlayıcısı olarak görülebilir. Bu bağlamda yapılacak çalışma ile bu alanda çalışma yapacak araştırmacılar için rehber niteliğinde olması, yıllar içinde çevre eğitiminin konularının dağıımı ve yöneliminin belirlenmesi, çevreyle ilgili yapılacak araştırmalar için kaynak olması amaçlanmaktadır.

Bu araştırmada 2012-2016 arasındaki yıllarda çevre eğitimi kapsamında yayımlanmış lisansüstü tezlerin incelenmesi amaçlanmıştır. Bu inceleme doğrultusunda yapılan çalışmada ulaşılan tezler incelenerek çevre eğitimi ile ilgili yapılan çalışmaların durumunun olduğu gibi ortaya konulması amaçlanmıştır.

\section{YÖNTEM}

Yapılan çalışmada nitel araştırmalardan durum çalışması kullanılmıştır. Durum çalışması diğer araştırma türlerinden farklı olarak 'nasıl' ve 'niçin' sorularını soran, araştırmacı tarafından kontrol edilemeyen bir olay veya olguyu kapsamlı bir incelemeye imkân tanıyan araştırma yöntemidir (Yıldırım \& Şimşek, 2013). Araştırmanın yapılmasında ayrıca tarihsel 
örgütlemeden de faydalanılmıştır. Tarihsel örgütleme zaman içerisindeki süreçlerin bir konu çerçevesinde gelişimi basamaklar hâlinde gösterilmesidir (Büyüköztürk, Çakmak, Akgün, Karadeniz \& Demirel, 2016).

Bu araştırma kapsamında çevre eğitimi ile ilgili yazılan doktora ve lisansüstü tezlerinin yıllara göre yönelimlerinin durum çalışması kullanılarak açığa çıkarılması hedeflenmiştir.

\section{1. Çalışma Evreni}

Bu araştırmaya dâhil edilecek çevre eğitimi kapsamında yayımlanmış lisansüstü tezleri belirlemek için YÖK Ulusal Veri Tabanı kullanılarak ulaşılmıştır. Ulaşılan 85 lisansüstü tezden, 20 'sinin içeriğine erişim izni olmadığı ve özetinde yeterli olmadığı düşünüldüğü için 65 lisansüstü tez örnekleme dâhil edilmiştir.

\subsection{Veri Toplama Araçları}

$\mathrm{Bu}$ araştırmada yayımlanmış tezler ele alınırken Yılmaz vd. (2015)'nin çalışmasında kullanılan kodlama formuna paralel bir form oluşturulması hedeflenmiştir. Bu doğrultuda araştırmacılar tarafından oluşturulan kodlama formu geliştirilmesinde ve kodlama sürecinin tamamında dört uzmana danışılarak uzman görüşü alınmıştır. Bu formda tezlerin; türlerine, yıllarına, yayımlandığı üniversitelere, çalışma gruplarına, araştırma konularına, yöntemlerine, veri toplama tekniklerine ve veri çözümleme tekniklerin neler olduğuna bakılmıştır.

\subsection{Verilerin Toplanması ve Analizi}

Bu araştırmada elde dilen veriler Yükseköğretim Kurulu'nun (YÖK) Ulusal tez merkezinden (tez.yok.gov.tr) yararlanılarak toplanmıştır. Araştırmada, nitel veri analizlerinden betimsel istatistik kullanılmıştır. Bunun için YÖK'ün resmi internet sitesinde bulunan ulusal tez merkezi sayfasındaki "Detaylı Tarama" seçeneği seçilmiş, yıl aralığı olarak "2012-2016" seçilmiş, anahtar kelime olarak "çevre eğitimi" yazılmış ve izin durumu "izinli" olarak seçilmiştir. Sonrasında 65 lisansüstü tez bilgisayar ortamında toplanmış ve oluşturulan kodlama formu doğrultusunda Excel ortamına aktarılmıştır. Bu araştırmaya dâhil edilen tezleri incelemek için araştırmacı tarafından kodlama formu oluşturulmuştur. Kodlama sonucu ulaşılan veriler yüzde, frekans ve tablo şeklinde sunulmuştur.

\section{BULGULAR}

Araştırmanın bu kısmında örnekleme dâhil edilen tezlere ilişkin bulgular sunulmuştur.

\section{1. Çalışma Kapsamında Ulaşılan Tezlere Ait Veriler}

Araştırma kapsamında belirlenen ölçütlere uygun; 53 yüksek lisans ve 12 doktora tez incelenmiştir ve elde edilen veriler aşağıdaki tablolarda sunulmuştur.

Tablo 1

Yayımlanan Tezlerin Türlerine Göre Dağılımı

\begin{tabular}{lll}
\hline Tür & Frekans & Yüzde \\
\hline Yüksek Lisans & 53 & 82 \\
Doktora & 12 & 18 \\
\hline Toplam & 65 & 100 \\
\hline
\end{tabular}

Yapılan alan yazın taraması neticesinde 2012-2016 yılları aralığında yayımlanan tezlerin $\% 82$ 'sinin yüksek lisans tezlerinden ve $\% 18$ 'inin doktora tezlerinden oluştuğu görülmektedir. 
Çevre eğitimi kapsamında yayımlanmış yüksek lisans ve doktora tezlerinin yıllara göre dağılımı Tablo 2'de sunulmuştur.

Tablo 2

Çevre Eğitimi Ile Ilgili Yayımlanan Tezlerin Yıllara Göre Dağılımı

\begin{tabular}{lllllll}
\hline Çalışma türü & 2012 & 2013 & 2014 & 2015 & 2016 & Toplam \\
\hline Yüksek Lisans & 23 & 14 & 11 & 5 & 0 & 53 \\
Doktora & 3 & 5 & 1 & 3 & 0 & 12 \\
Toplam & 26 & 19 & 12 & 8 & 0 & 65 \\
\hline
\end{tabular}

Tablo 2 incelendiğinde çevre eğitimi kapsamında yayımlanmış toplam lisansüstü tezlerinin \%40'। 2012 yılında, \%30'u 2013 yılında, \%18'i 2014 yılında ve \%12'si 2015 yılında yayımlandığı görülürken 2016 yılında yayımlanan (erişime izin verilen) lisansüstü tez görülmemiştir.

Çevre eğitimi kapsamında yayımlanmış lisansüstü tezlerin yapıldığı üniversitelerin yıllara göre dağılımı Tablo 3'te gösterilmiştir.

Tablo 3

Çevre Eğitimi Kapsamında Yayımlanmış Lisansüstü Tezlerin Yapıldığı Üniversitelerin Yıllara Göre Dağııımı

\begin{tabular}{|c|c|c|c|c|c|c|c|c|c|}
\hline \multirow{3}{*}{ Üniversite } & \multicolumn{4}{|c|}{ Yüksek Lisans Tezi } & \multicolumn{4}{|c|}{ Doktora Tezi } & \multirow{3}{*}{ Toplam } \\
\hline & 2012 & 2013 & 2014 & 2015 & 2012 & 2013 & 2014 & 2015 & \\
\hline & \multicolumn{8}{|c|}{ Frekans } & \\
\hline Gazi Üniversitesi & 3 & 7 & 2 & 1 & & 2 & 1 & 1 & 17 \\
\hline $\begin{array}{ll}\text { Dokuz } & \text { Eylül } \\
\text { Üniversitesi } & \end{array}$ & 2 & 1 & 1 & & & & & & 4 \\
\hline İnönü Üniversitesi & 1 & 1 & & & 1 & 1 & & & 4 \\
\hline $\begin{array}{ll}\text { Karadeniz } & \text { Teknik } \\
\text { Üniversitesi } & \end{array}$ & 1 & 2 & & & & 1 & & & 4 \\
\hline Atatürk Üniversitesi & & & & 1 & & 1 & & 1 & 3 \\
\hline $\begin{array}{l}\text { Hacettepe } \\
\text { Üniversitesi }\end{array}$ & 2 & 1 & & & & & & & 3 \\
\hline Abant İzzet Baysal & 1 & & 1 & & & & & & 2 \\
\hline Üniversitesi & & & & & & & & & \\
\hline $\begin{array}{ll}\text { Ahi } & \text { Evran } \\
\text { Üniversitesi } & \end{array}$ & 2 & & & & & & & & 2 \\
\hline Erciyes Üniversitesi & 2 & & & & & & & & 2 \\
\hline Fatih Üniversitesi & & & 2 & & & & & & 2 \\
\hline $\begin{array}{l}\text { İhsan Doğramacı } \\
\text { Bilkent Üniversitesi }\end{array}$ & 2 & & & & & & & & 2 \\
\hline $\begin{array}{l}\text { Muğla Sıtkı Koçman } \\
\text { Üniversitesi }\end{array}$ & 2 & & & & & & & & 2 \\
\hline
\end{tabular}




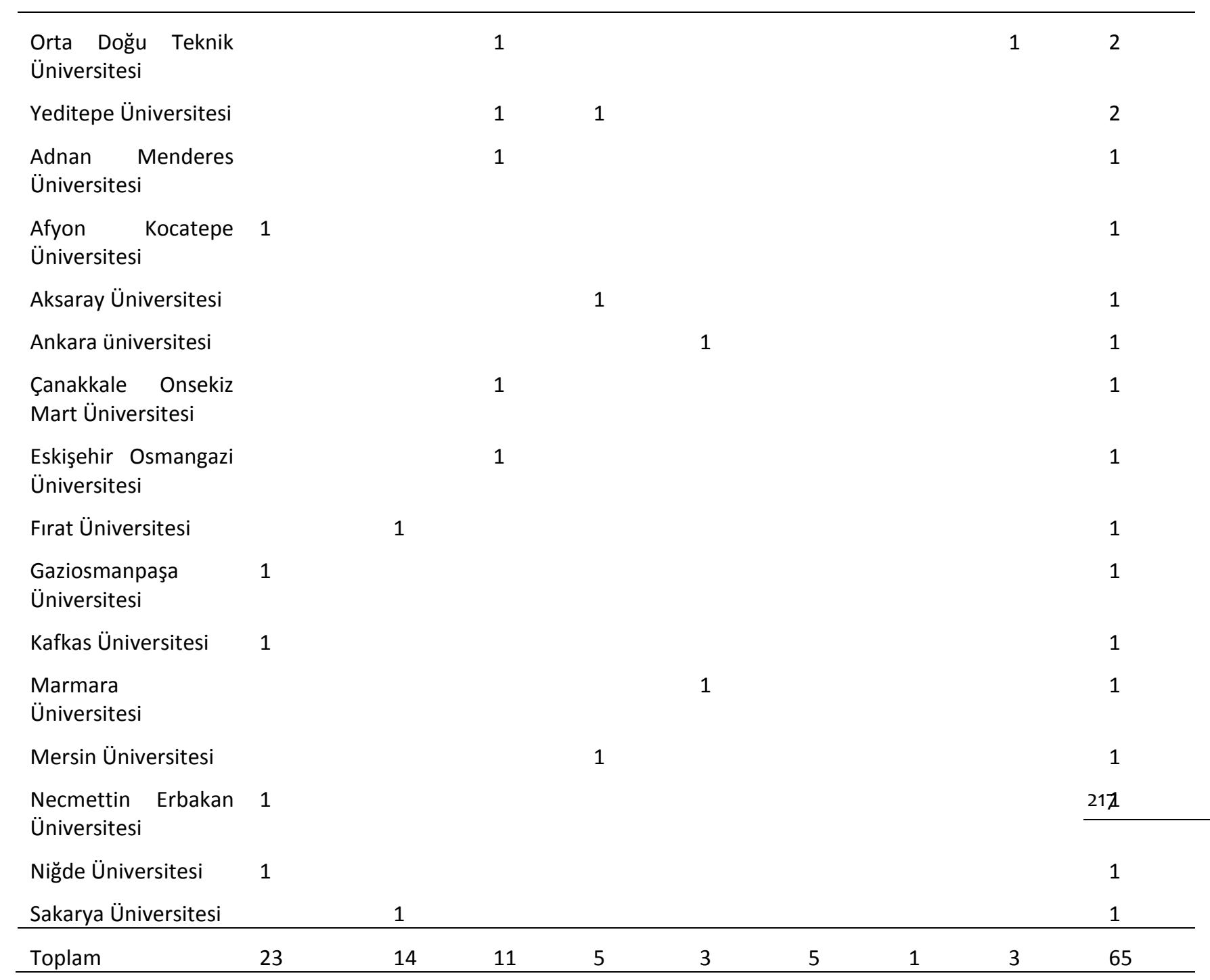

Yukarıdaki tablo incelendiğinde çevre eğitimi kapsamında yayımlanmış lisansüstü tezlerin \%26'sının Gazi Üniversitesinde, \%6'sının; Dokuz Eylül, İnönü ve Karadeniz Teknik Üniversitelerinde yayımlandığı görülmektedir.

Çevre eğitimi kapsamında yayımlanmış lisansüstü tezlerin çalışma grupları ve yıllara göre dağılımları Tablo 4'de gösterilmiştir.

Tablo 4

Çevre Eğitimi Kapsamında Yayımlanmış Lisansüstü Tezlerde Çalışılan Grupların Yıllara Göre Dağılımı

\begin{tabular}{llllll}
\hline Çalışma Grubu & 2012 & 2013 & 2014 & 2015 & Toplam \\
\hline $\begin{array}{llll}\text { Frekans } \\
\text { *ilköğretim }\end{array}$ & 10 & 9 & 2 & 3 & 24 \\
$\begin{array}{l}\text { Öğrencileri } \\
\text { * Ortaöğretim }\end{array}$ & 8 & 4 & 4 & 2 & 18 \\
$\begin{array}{l}\text { Öğrencileri } \\
\text { *Yükseköğretim }\end{array}$ & 6 & 5 & 2 & 2 & 15 \\
$\begin{array}{l}\text { Öğrencileri } \\
\text { Belge/Doküman }\end{array}$ & 3 & & 1 & 1 & 5
\end{tabular}




\begin{tabular}{|c|c|c|c|c|c|}
\hline Öğretmen & 2 & & 2 & 1 & 5 \\
\hline *Yetişkinler/Halk & 1 & & 2 & & 3 \\
\hline $\begin{array}{l}\text { Okul Öncesi } \\
\text { Öğrencileri }\end{array}$ & 1 & & & 1 & 2 \\
\hline *Öğretim Üyesi & & & & 1 & 1 \\
\hline Toplam & 31 & 18 & 13 & 11 & 73 \\
\hline
\end{tabular}

*işaretli gruplar tezde aynı anda tercih edilmiştir.

Tablo 4 incelendiği zaman tercih edilen çalışma grupların hepsinde nicel olarak yıllara göre azalma görülmüştür. En fazla tercih edilen çalışma gruplarının ilköğretim (\%37) ve ortaöğretim (\%28) olduğu görülmüştür. En az tercih edilen grubun ise okul öncesi (\%2) olduğu görülmüştür.

Çevre eğitimi kapsamında yayımlanmış lisansüstü tezlerin araştırma konularının yıllara göre dağılımları Tablo 5'te gösterilmiştir.

Tablo 5

Çevre Eğitimi Kapsamında Yayımlanmış Lisansüstü Tezlerin Araştırma Konularının Yıllara Göre Dağılımı

\begin{tabular}{|c|c|c|c|c|c|}
\hline Konu & 2012 & 2013 & 2014 & 2015 & Toplam \\
\hline \multicolumn{6}{|c|}{ Frekans } \\
\hline *Çevre Eğitimi & 20 & 9 & 6 & 8 & 43 \\
\hline $\begin{array}{l}\text { *Çevreye Yönelik } \\
\text { Tutum }\end{array}$ & 7 & 4 & & 3 & 14 \\
\hline *Çevre Sorunları & 2 & 3 & 1 & 1 & 7 \\
\hline *Çevre Bilinci & 3 & 1 & & 1 & 5 \\
\hline $\begin{array}{l}\text { *Çevre } \\
\text { Okuryazarlığı }\end{array}$ & 1 & 2 & & 1 & 4 \\
\hline $\begin{array}{l}\text { *Fen ve Tek. } \\
\text { Programı }\end{array}$ & 1 & 1 & & 2 & 4 \\
\hline $\begin{array}{l}\text { *Sürdürülebilir } \\
\text { Çevre }\end{array}$ & 3 & 1 & & & 4 \\
\hline *Biyolojik Çeşitlilik & 4 & & & & 4 \\
\hline *Çevre Bilgisi & 2 & & 1 & & 3 \\
\hline Çevre Kimliği & 1 & 1 & 1 & & 3 \\
\hline *Eko-okul & 1 & & & & 1 \\
\hline $\begin{array}{ll}\text { Çevresel } & \text { Geri } \\
\text { Dönüşüm } & \end{array}$ & & 1 & & & 1 \\
\hline Çevre Kirliliği & & 1 & & & 1 \\
\hline Doğa Algısı & 1 & & & & 1 \\
\hline Karbon Ayak İzi & 1 & & & & 1 \\
\hline Küresel Isınma & & 1 & & & 1 \\
\hline Toplam & 47 & 25 & 9 & 16 & 97 \\
\hline
\end{tabular}


*işaretli konular tezlerde aynı anda tercih edilmiştir.

Çevre eğitimi kapsamında yayımlanmış lisansüstü tezler incelendiğinde işlenen araştırma konulara bakıldığında 16 farklı konu tespit edilmiştir. Elde edilen bulgular incelendiğinde en fazla seçilen araştırma konularının; \%66'sının çevre eğitimi, \%22'sinin çevreye yönelik tutum ve \%11'inin çevre sorunlarından oluştuğu görülmüştür.

Çevre eğitimi kapsamında yayımlanmış lisansüstü tezlerinde kullanılan yöntemler Tablo 6'da gösterilmiştir.

Tablo 6

Çevre Eğitimi ile Ilgili Yayımlanan Tezlerde Kullanılan Yöntemler

\begin{tabular}{|c|c|c|c|c|}
\hline \multicolumn{5}{|c|}{ Araştırma Yöntemi } \\
\hline Nicel Araştırma & Frekans & Nitel Araştırma & Frekans & Karma Yöntem \\
\hline Tarama Modeli & 22 & Tarama Modeli & 8 & 10 \\
\hline Deneysel Desen & 10 & Betimsel Çalışma & 2 & \\
\hline Betimsel Çalışma & 2 & Eylem Araştırma & 1 & \\
\hline \multirow[t]{3}{*}{$\begin{array}{l}\text { Path } \\
\text { Yöntemi }\end{array}$} & 1 & $\begin{array}{ll}\text { Özel } & \text { Durum } \\
\text { Çalışması } & \end{array}$ & 5 & \\
\hline & & Olgubilim & 1 & \\
\hline & & Örnek Olay & 2 & \\
\hline
\end{tabular}

Çevre eğitimi kapsamında yayımlanmış lisansüstü tezlerde kullanılan modeller 3 grup içerisinde ele alınmıştır. Çıkan sonuçlara bakıldığında araştırmalarda en fazla kullanılan modelin tarama modeli (\%34) olduğu görülmüştür. Bunu karma yöntem (\%15) ve deneysel desen (\%15) izlemektedir.

Çevre eğitimi kapsamında yayımlanmış lisansüstü tezlerindeki veri toplama teknikleri Tablo 7'de sunulmuştur.

Tablo 7

Çevre Eğitimi Kapsamında Yayımlanmış Tezlerdeki Veri Toplama Teknikleri

\begin{tabular}{ll}
\hline Veri Toplama Teknikleri & Frekans \\
\hline *Yazılı Veri Toplama & 56 \\
*Görüşme & 19 \\
*Belge Tarama & 6 \\
*Gözlem & 3 \\
Toplam & 84 \\
\hline
\end{tabular}

*işareti kullanılan tekniklerin tezlerde aynı anda tercih edildiğini göstermektedir.

Veri toplama teknikleri incelendiği zaman tezlerin \%86'sında yazılı veri toplama tekniğinin kullanıldığı görülmektedir. Bu bağlamda yazııı veri toplama araçlarının detaylı olarak incelenmesi uygun görülmüş ve dört başlık altında incelenmiştir. Kullanılan yazılı veri toplama tekniğinde araştırmacıların \%39'unun ölçme aracı geliştirdiği ve \%42'sinin geliştirilmiş aracı kullandığı görülmüştür. 
Tablo 8

Tezlerde Kullanılan Yazılı Veri Toplama Teknikleri

Yazılı Veri Toplama

\begin{tabular}{|c|c|c|c|c|c|}
\hline & $\begin{array}{l}\text { Ölçme Aracı } \\
\text { Geliştirme }\end{array}$ & $\begin{array}{c}\text { Ölçme Aracı } \\
\text { Uyarlama }\end{array}$ & $\begin{array}{c}\text { Geliştirilmiş } \\
\text { Araç Kullanma }\end{array}$ & $\begin{array}{c}\text { Uyarlanmış } \\
\text { Araç Kullanma }\end{array}$ & Toplam \\
\hline $\begin{array}{l}\text { *Çevre Kimliği } \\
\text { Ölçeği }\end{array}$ & & 1 & & 1 & 2 \\
\hline $\begin{array}{l}\text { *Çevre Davranış } \\
\text { Ölçeği }\end{array}$ & 3 & & 5 & 1 & 9 \\
\hline $\begin{array}{l}\text { *Çevre Tutum } \\
\text { Ölçeği }\end{array}$ & 6 & & 15 & 3 & 24 \\
\hline $\begin{array}{l}\text { *Çevre İnanç } \\
\text { Ölçeği }\end{array}$ & 1 & & & 1 & 2 \\
\hline $\begin{array}{l}\text { *Çevre Görüş } \\
\text { Ölçeği }\end{array}$ & & & 2 & & 2 \\
\hline $\begin{array}{l}\text { *Çevre Bilinci } \\
\text { Ölçeği }\end{array}$ & 5 & & 2 & & 7 \\
\hline *Çevre Başarı Testi & 4 & & 2 & & 6 \\
\hline $\begin{array}{l}\text { *Çevre Eğitimi Öz- } \\
\text { yeterlilik Ölçeği }\end{array}$ & 2 & & & 1 & 3 \\
\hline *Çevre Bilgi Testi & 4 & 1 & 5 & & 10 \\
\hline $\begin{array}{c}\text { Çocuklar İçin Çevre } \\
\text { Ölçeği }\end{array}$ & 1 & & 1 & & 2 \\
\hline $\begin{array}{l}\text { Biyoçeşitliliğin } \\
\text { Azalması ile İlgili } \\
\text { Tutum Ölçeği }\end{array}$ & 1 & 1 & & & 2 \\
\hline $\begin{array}{c}\text { Ekolojik Paradigma } \\
\text { Ölçeği }\end{array}$ & & & & 1 & 1 \\
\hline $\begin{array}{c}\text { *Çevre Okuryazalık } \\
\text { Ölçeği }\end{array}$ & & & 2 & 1 & 3 \\
\hline *Anket & 8 & 1 & 4 & 3 & 16 \\
\hline Toplam & 35 & 4 & 38 & 12 & 89 \\
\hline
\end{tabular}

*işaretli araçlar araştırmacı tarafından aynı anda tercih edildiğini göstermektedir.

Çevre eğitimi kapsamında yayımlanmış lisansüstü tezlerin veri analizinde kullanılan veri çözümleme tekniklerinin yıllara göre dağılımı Tablo 9'da verilmiştir. 
Tablo 9

Veri Analizinde Kullanılan Veri Çözümleme Tekniklerinin Yıllara Göre Dağılımı

\begin{tabular}{llllll}
\hline $\begin{array}{l}\text { Veri Çözümleme } \\
\text { Tekniği }\end{array}$ & 2012 & 2013 & 2014 & 2015 & Toplam \\
\hline $\begin{array}{l}\text { Frekans } \\
\text { *Parametrik Testler }\end{array}$ & 11 & 13 & 5 & 3 & 32 \\
*Parametrik & 1 & 3 & 2 & 4 & 10 \\
$\begin{array}{l}\text { Olmayan Testler } \\
\text { *Betimsel İstatistik }\end{array}$ & 3 & 1 & 1 & 1 & 6 \\
${ }^{*}$ Betimsel/içerik & 14 & 10 & 3 & 3 & 30 \\
Çözümlemesi & 29 & 27 & 11 & 11 & 78 \\
\hline
\end{tabular}

*İ̧saretli veri çözümleme teknikleri araştırmacı tarafından aynı anda kullanıldığını göstermektedir.

Çevre eğitimi kapsamında yayımlanmış lisansüstü tezlerinde veri analizinde tercih edilen veri çözümleme tekniklerine bakıldı̆ıında; tekniklerin \%49'unun parametrik testler, $\% 46$ 'sının betimsel/içerik çözümlemesi, $\% 15^{\prime}$ inin parametrik olmayan testler ve $\% 9^{\prime}$ unun betimsel istatistik olduğu görülmüştür.

\section{SONUÇ, TARTIŞMA VE ÖNERILER}

Araştırma sonucunda çıkan bulgular çeşitli başlıklar altında aşağıda tartışılmıştır.

Türe Göre Dağııım

Yapılan çalışma kapsamında 2012-2016 yılları arasında toplam 65 tez incelenmiş ve tezlerde nicelik olarak yüksek lisans tezlerinin $(n=53)$ doktora tezlerinden $(n=12)$ fazla olduğu görülmüştür. Bu bulgular Yılmaz vd. (2015)'nin yaptıkları çalışmayla paralellik göstermektedir. Ayrıca iki çalışmadaki yıl aralığı ile yayımlanan tez sayıları karşılaştırıldığında son beş yılda yayımlanan tezlerin sayısında ciddi bir artış görülmektedir ve bu oranın giderek artacağı söylenebilir (Leeming vd. 1993; Akdemir \& Karakuş, 2016; Onwuegbuzie, \& Daniel, 2003).

\section{Yıllara Göre Dağılım}

Yapılan çalışmada yayımlanan tezlerin yıllara göre dağılımı incelendiğinde en çok 2012 yılında ( $n=26)$ tezin yayımlandığı görülmüşken buna karşıık en az 2015 yılında $(n=8)$ yayımlandığı görülmüştür. Son olarak 2016 yılında hiçbir tezin (erişime izin verilen) yayımlanmadığı görülmüştür. Yılmaz vd. (2015)'nin yaptığı çalışmada 1992-2011 yılları arasında nicel olarak düzenli bir artış görülmüştür. Yapılan çalışmada ise 2012-2016 yılları arasında nicel olarak düzenli bir düşüş gözlemlenmiştir. Bunun sebebi son yıllarda yayımlanan tezlerin erişime açık olmamaları ve örneklem dışında kalmalarıdır.

\section{Üniversitelerin Yıllara Göre Dağılımı}

Çevre eğitimi ile ilgili 2012-2016 yılları arasında yayımlanan yüksek lisans ve doktora tezleri çalışmaların yapıldığı üniversite ve yıllara göre analiz edildiğinde en fazla Gazi ( $n=17)$, Karadeniz Teknik $(n=4)$, İnönü $(n=3)$, Dokuz Eylül $(n=4)$ üniversitelerinde yapıldığı görülmektedir. Yılmaz vd. (2015)'nin yaptığı çalışmada da en çok Gazi ( $n=51)$ üniversitesinde tezlerin yapıldığı belirtilmiştir. Bu doğrultuda Gazi üniversitesinin yıllar içinde çevre eğitimi ile ilgili tez yayımlama sıklığının sabit olduğu ve geri kalan üniversitelerin ise az sayıda çevre eğitimi üzerine tez yayımladığı görülmüştür. 


\section{Çalıșma Gruplarının Yıllara Göre Dağı̆ımı}

Çevre eğitimi kapsamında yayımlanmış lisansüstü tezlerde tercih edilen çalışma grupları analiz edilmiştir. Analizde elde edilen bulgulara bakıldığında 8 çalışma grubu tespit edilmiştir. İncelenen tezlere bakıldığında en fazla çalışılan gruplarının; ilköğretim öğrencileri $(n=24)$, ortaöğretim öğrencileri $(n=18)$ ve yükseköğretim öğrencileri $(n=15)$ olduğu görülmektedir. Yapılan diğer alan yazın çalışmaları elde edilen sonuçlarla uyumludur (Yaşar \& Papatğa, 2015; Yılmaz vd., 2015; Göçen \& Okur, 2015; Şahin, Calp, Bulut \& Kuşdemir, 2013).

\section{Araştırma Konularının Yıllara Göre Dağılımı}

2012-2016 arasındaki kapsamında incelenen yayımlanmış lisansüstü tezlerde 16 farklı konunun işlendiği görülmüştür. Bu konularda en çok tercih edilen konular; çevre eğitimi ( $n=43)$, çevreye yönelik tutum ( $n=14)$ ve çevre sorunları $(n=7)$ olduğu görülmüştür. Araştırmada en az küresel ısınma $(n=1)$, karbon ayak izi $(n=1)$, çevre kirliliği $(n=1)$, çevresel geri dönüşüm $(n=1)$, eko-okul ( $n=1)$, doğa algısı $(n=1)$ konularına değinildiği görülmüştür. Yılmaz vd. (2015)'nin yaptıkları çalışmada da en fazla işlenen araştırma konularının benzer olduğu görülmüştür. Kısaca 1972 yılından günümüze doğru alandaki bazı konular doyum noktasına ulaşırken birçok konu üzerinde de yeterli araştırma olmadığı görülmektedir (Yılmaz vd., 2015; Şimşek vd., 2008; Şimşek vd., 2009).

\section{Veri Toplama Tekniklerinin Dağılımı}

Çevre eğitimi kapsamında Türkiye içinde 2012-2016 arasındaki yıllarda yayımlanmış lisansüstü tezlerinin veri toplama teknikleri ele alınmıştır. Tezler incelendiğinde önceki çalışmaya (Yılmaz vd., 2015) da benzerlik göstermesi açısından yazılı veri toplama, görüşme, gözlem ve belge tarama şeklinde 4 başlık belirlenmesi uygun görülmüş ve buna göre sınıflandırılmıştır. İncelenen tezler arasında en fazla yazılı veri toplama tekniği $(n=56)$ ve geliştirilmiş ölçek kullanıldığı $(n=38)$ görülmüştür. Kullanılan ölçekler içerisinde en çok çevre tutum ölçeğinin ve çevreye yönelik hazırlanan ölçeklerin kullanıldığı görülmektedir. Birçok araştırmacının ölçek veya anket kullandığı fakat gözlem ve görüşme teknikleri gibi diğer tekniklere yeterince yer verilmediği literatürdeki diğer çalışmalarda da görülmektedir (Yılmaz vd., 2015; Erol \& Tüzel; Şahin vd., 2013; Kozikoğlu \& Senemoğlu, 2015).

\section{Kullanılan Araştırma Yöntemleri}

Araştırma sonucunda kullanılan yöntemler arasında en fazla nicel yöntemin ( $n=35)$ kullanıldığı ve nicel desenler içinde ise en fazla tarama $(n=22)$ deseninin kullanıldığı görülürken en az; eylem $(n=1)$ araştırmalarının kullanıldığı görülmektedir. Yapılan diğer çalışmalarda bu bulguları destekler niteliktedir (Yılmaz vd. 2015; Şahin vd., 2013; Erol \& Tüzel, 2012; Göçen \& Okur, 2015; Kozikoğlu \& Senemoğlu, 2015). Bu kapsamda bakıldığında yöntemin nicel ve desenin tarama olması araştırmacıların bulguları daha çok sayısallaştırmaya çalıştığı söylenebilir (Erol \& Tüzel, 2012).

\section{Veri Analizi}

Çevre eğitimi kapsamında Türkiye içinde 2012-2016 arasındaki yıllarda yayımlanmış lisansüstü tezlerindeki araştırmalarda kullanılan veri çözümleme tekniklerinin yıllara göre değişimi analiz edilmiştir. Araştırmada elde edilen bulgular doğrultusunda tezler içerisinde en fazla kullanılan veri çözümleme tekniklerin; parametrik testler $(n=32)$ ve betimsel/içerik çözümlemesi $(n=30)$ olduğu görülmektedir. Yapılan diğer literatür çalışmaları incelendiğinde benzer sonuçlar görülmüştür (Şahin, Calp, Bulut \& Kuşdemir, 2013; Duygulu \& Sezgin, 2015; Göçen \& Okur, 2015; Yılmaz vd., 2015; Yaşar \& Papatğa, 2015; Büyükikiz, 2014). 
Çevre eğitimi kapsamında yayımlanmış lisansüstü tezler incelenmiş ve 2012'den günümüze doğru yayımlanan tezlerde sayıca azalma fark edilmiştir. 2016 yılında ise yayımlanmış bir çalışmaya henüz rastlanılmamıştır. Çevre eğitimine olan bu farkındalığın azalmasını önlemek ve üzerinde durulmayan alanlara araştırmacıların yöneltilmesi adına üniversitelerde lisansüstü seçmeli dersi olarak çevre eğitimi dersi açılabilir.

Yılmaz vd. (2015)'nin yaptığı çalışma ile paralellik gösteren sonuçlar bulunmuş ve çevre eğitimi kapsamında ele alınan tez konularına bakıldığında araştırmacıların yine çoğunlukla çevreye yönelik tutum, çevre okuryazarlığı, çevre bilinci, çevreye yönelik davranış gibi konular üzerine yoğunlaştıkları görülmüştür. Tezlerin analizinden elde edilen bulgular doğrultusunda eko-okul, çevresel geri dönüşüm, çevre kirliliği, doğa algısı, karbon ayak izi ve küresel ısınma konuları üzerine yapılan araştırmaların diğerlerine oranla sayıca az kaldığı görülmüştür. Bu bağlamda, bir önceki çalışma da göz önünde bulundurularak elde edilen bulgular doğrultusunda sayıca az olan çalışmalar da dikkate alınmalıdır.

Çevre eğitimi kapsamında yayımlanmış lisansüstü tezler araştırmada seçilen yöntemler açısından incelendiğinde tarama modelinin en fazla kullanılan araştırma modeli olduğu tespit edilmiştir. Bunun yanı sıra nitel tarama ve deneysel desen modelleri de sayıca fazla olduğu görülmüştür. Özellikle çevre eğitimi kapsamında eylem araştırmasının sayıca az ve yetersiz olduğu için çevre eğitimi konusunda eylem araştırmaları yapılması araştırmacılara önerilebilir. Son olarak sayıca fazla olan bu deneysel çalışmaların toplanması ve ülkemizde verilen çevre eğitiminin çeşitli değişkenlere (akademik başarı, tutum, motivasyon vd.) göre etkililiğinin araştırılması adına meta analiz çalışmaları yapılabilir.

\section{KAYNAKLAR}

Akdemir, H., \& Karakuş, M. (2016). Yaratıcı drama yönteminin akademik başarı üzerine etkisi: bir meta-analiz çalışması. International Journal of Active Learning, 1(2), 55-67.

Büyükikiz, K. K. (2014). Yabancılara Türkçe öğretimi alanında hazırlanan lisansüstü tezler üzerine bir inceleme. Mustafa Kemal Sosyal Bilimler Enstitüsü Dergisi, 11(25), 203-213.

Büyüköztürk, Ş., Çakmak, E.K., Akgün, Ö.E., Karadeniz, Ş. \& Demirel, F. (2016). Bilimsel araştırma yöntemleri. Ankara: Pegem

Duygulu, E. \& Sezgin, O. B. (2015). Türkiye'de örgütsel davranış yazını doktora tezlerine yönelik bir inceleme. İs ve insan Dergisi, 2(1), 13-25.

Erol, E. \& Tüzel, E. (2015). Türkiye'de eğitim yönetimi teftişi planlaması ve ekonomisi anabilim dalı doktora programlarında tamamlanan tezlerin eğitim sosyolojisi kapsamında değerlendirilmesi. Sosyoloji Dergisi, 3(30), 297-316.

Erten, S. (2005). Okul öncesi öğretmen adaylarında çevre dostu davranışların araştırılması. Hacettepe Üniversitesi Eğitim Fakültesi Dergisi, 28(28).

Ertürk, H. (2009). Çevre bilimleri. Bursa: Ekin basım yayın dağıtım

Geçit, Y. \& Kartal, A. (2010). Türkiye'deki sosyal bilgiler eğitimi araştırma konuları üzerine bir inceleme. International Conference On New Trends in Education And Their Implications, 11(13), 101-107.

Göçen, G. ve Okur, A. (2015). Ortaokula yönelik söz varlığı araştırmalarının incelenmesi: Tezler. Ana Dili Eğitimi Dergisi, 3(1), 64-79.

Görmez, K. (2010). Çevre sorunları. Ankara: Nobel yayın dağıtım 
İleri, R. (1998). Çevre eğitimi ve katılımın sağlanması. Ekoloji Çevre Dergisi, 7(28), 3-9.

Jensen, B. B., \& Schnack, K. (2006). The action competence approach in environmental education: Reprinted from Environmental Education Research (1997) 3(2), pp. 163178. Environmental education research, 12(3-4), 471-486.

Karadağ E. (2009). Eğitim bilimleri alanında yapılmış doktora tezlerinin tematik açıdan incelenmesi. Ahi Evran Eğitim Fakültesi Dergisi, 10(3), 75-87.

Karkın, A. M. (2011). Müzik bilimleri alanında yapılan lisansüstü tezlerin incelenmesi. Inönü Üniversitesi Sanat ve Tasarım Dergisi, 1(2), 143-149

Keçeli, A. \& Sarıusta, F. (2014). Sorun temelli- çözüm odaklı coğrafya! Yüksek lisans ve doktora tez çalışmaları üzerine bir inceleme. Süleyman Demirel Sosyal Bilimler Enstitüsü Dergisi, 2(20), 85-100

Kozikoğlu, ì. \& Senemoğlu, N. (2015). Eğitim programları ve öğretim alanında yapılan doktora tezlerinin içerik analizi (2009-2014). TED Eğitim ve Bilim Dergisi, 40(182), 29-41

Leeming, F. C., Dwyer, W. O., Porter, B. E., \& Cobern, M. K. (1993). Outcome research in environmental education: A critical review. The Journal of Environmental Education, 24(4), 8-21.

Onwuegbuzie, A. J., \& Daniel, L. G. (2003). Typology of analytical and interpretational errors in quantitative and qualitative educational research. Current Issues in Education, 6(2).

Önder, A. \& Özkan, B. (2013). Sürdürülebilir çocuk gelişimi okul öncesinde etkinliklerle çevre eğitimi. Ankara: Anı yayıncılık

Özdemir, O. (2010). Yeni bir çevre eğitimi perspektifi: "Sürdürülebilir gelişme amaçlı eğitim". Eğitim ve Bilim, 32(145), 23-38.

Sevinç, K. (2013). Türkiye'de din psikolojisi alanında yapılan lisansüstü tezler üzerine bir inceleme. Sakarya ilahiyat Fakültesi Dergisi, 15(28), 243-269.

Stapp, W. B. (1969). The concept of environmental education. Environmental Education, 1(1), 30-31.

Stockholm Declaration (1972). Declaration of the United Nations Conference on the Human Environment. www.unep.org/documents. multilingual/default.asp?documentid=97\&articleid=1503 sayfasından erişilmiştir.

Sümer, G. Ç. (2009). Türkiye'de yerel yönetimler yazınında çevre: lisansüstü tezler üzerinden bibliyografik bir inceleme. C.Ü. Iktisadi ve Idari Bilimler Dergisi, 10(2), 57-72.

Şahin, D., Calp, Ş., Bulut, P. \& Kuşdemir, Y. (2013). Sınıf öğretmenliği eğitimi bilim dalında yapılmış lisansüstü tezleri çeşitli kriterlere göre incelenmesi. Zeitschrift Für Die Welt Der Türken, 5(3), 187-205.

Şahin, N. F., Cerrah, L., Saka, A., \& Şahin, B. (2004). Yüksek öğretimde öğrenci merkezli çevre eğitimi dersine yönelik bir uygulama. Gazi Üniversitesi Gazi Eğitim Fakültesi Dergisi, 24(3).

Şimşek, A., Özdamar, N., Becit, G., Kılıçer, K., Akbulut, Y. \& Yıldırım, Y. (2007). Türkiye eğitim teknolojisi araştırmalarında güncel eğilimler. I. Uluslararası Bilgisayar ve Öğretim Teknolojileri Sempozyumu'nda sunulmuş bildiri, Çanakkale Onsekiz Mart Üniversitesi, Çanakkale. 
Şimşek, A., Özdamar, N., Becit, G., Kılıçer, K., Akbulut, Y., \& Yıldırım, Y. (2008). Türkiye'deki eğitim teknolojisi araştırmalarında güncel eğilimler. Selçuk Üniversitesi Sosyal Bilimler Enstitüsü Dergisi, (19), 439-458.

Şimşek, A., Özdamar, N., Uysal, Ö., Kobak, K., Berk, C., Kılıçer, T., \& Çiğdem, H. (2009). íkibinli yıllarda Türkiye'deki eğitim teknolojisi araştırmalarında gözlenen eğilimler. Kuram ve Uygulamada Eğitim Bilimleri Dergisi, 9(2), 115-120.

Toptaş, B. (2013). Türkiye'de piyano üzerine yapılmış lisansüstü çalışmalar. The Journal of Academic Social Science Studies, 6(3), 715-728

Turna, Ö. \& Bolat, M. (2015). Eğitimde disiplinlerarası yaklaşımın kullanıldığı tezlerin analizi. Ondokuz Mayıs Eğitim Fakültesi Dergisi, 34(1), 35-55.

UNESCO, (1977). Intergovernmental Conference on Environmental Education. http://www.gdrc.org/uem/ee/EE-Tbilisi_1977.pdf sayfasından erişilmiştir.

Ünal, S., \& Dımışkı, E. (1999). UNESCO-UNEP himayesinde çevre eğitiminin gelişimi ve Türkiye'de ortaöğretim çevre eğitimi. Hacettepe Üniversitesi Eğitim Fakültesi Dergisi, 16(17), 142-154.

Yaşar, Ş. \& Papatğa, E. (2015). İlkokul matematik derslerine yönelik yapılan lisansüstü tezlerin incelenmesi. Trakya Eğitim Fakültesi Dergisi, 5(2), 113-124.

Yıldırım, A. \& Şimşek, H. (2013). Sosyal bilimlerde nitel araştırma yöntemleri. Ankara: Seçkin.

Yıldız, K., Sipahioğlu Ş.\& Yılmaz, M. (2008). Çevre bilimi ve eğitimi. Ankara: Gündüz eğitim ve yayıncılık

Yılmaz, A., Morgil, İ., Aktuğ, P., \& Göbekli, ì. (2002). Ortaöğretim ve üniversite öğrencilerinin çevre, çevre kavramları, ve sorunları konusundaki bilgileri ve öneriler. Hacettepe Üniversitesi Eğitim Fakültesi Dergisi, 22(22).

Yılmaz, Ş., Aydın, F. \& Bahar, M. (2015). 1992-2011 yılları arasında çevre eğitimi ile ilgili yayımlanan yüksek lisans ve doktora tezlerindeki genel yönelimlerin belirlenmesi. Adıyaman Sosyal Bilimler Enstitüsü Dergisi, 8(19), 383-413. 


\section{SUMMARY}

That environmental problems will affect not only a certain segment but also every living creature, and therefore the whole world must consider that issue. In line with the necessity of environmental education, everyone was included in the target group. Also Since 1970s, environmental education has started to be considered at the level of higher education as it is in all education levels in many countries. Therefore, as in other countries in our country, environmental education has gained more importance every year. This interest in environmental education in recent years has led to a wealth of literature. The theses prepared in this process provide solutions to the existing problems in the literature with the guidance of many studies. But it may be difficult for researchers who are new to work to try to figure out what the overall trend is in these quantitatively lot of theses. For this reason within the scope of this research, it was aimed to expose the tendencies of doctoral and postgraduate theses written about environmental education according to years by using case study. Also Yılmaz, Aydın \& Bahar (2015) made a similar research that examined the theses related to environmental education published until 1992-2011. Therefore this study can be seen as a continuation and complement of the work of Yılmaz et al. (2015).

In the study conducted, case study was used from qualitative researches. The case study is a research method that allows a comprehensive review of an event or phenomenon that can not be controlled by the investigator, asking 'how' and 'why', unlike other types of research. The National Education Database of the Higher Education Council was used to determine published postgraduate dissertations in the scope of environmental education to be included in this research. 53 master's and 12 doctoral thesis, including a total of 65 theses were examined. In this direction, the coding form created by the researchers was developed and expert opinion was obtained by consulting four experts in the entire coding period. While analyzed the data in the study, descriptive statistics were used. Then the coding result is presented in percent, frequency and table format.

Findings showed that the maximum release from Gazi University. Research has been shown to be the most preferred primary school students of the working group; as a research subject was attitude towards the environment; method was descriptive survey model; descriptive parametric tests / content analysis. We found parallel result with previous study. Research on eco-school, environmental recycling, environmental pollution, nature perception, carbon footprint, and global warming has been found to be fewer in the findings from the analysis of the theses than the others. In this context, it should be taken into consideration that the few study area which obtained by findings. Particularly in the context of environmental education, action research is few and inadequate. Finally, meta-analysis studies can be carried out in order to collect these empirical studies which are numerous and to examine the effect of environmental education given in our country on various variables (academic achievement, attitude, motivation etc.). 